\title{
Children's Engineering Design Thinking Processes: The Magic of the ROBOTS and the Power of BLOCKS (Electronics)
}

\author{
Sarika Kewalramani ${ }^{{ }^{*}}$, Ioanna Palaiologou ${ }^{2}$, Maria Dardanou ${ }^{3}$ \\ ${ }^{1}$ Monash University, AUSTRALIA \\ 2 University College London, UNITED KINGDOM \\ ${ }^{3}$ The Arctic University of Norway, NORWAY
}

Received 1 August 2019 - Revised 10 October 2019 • Accepted 21 October 2019

\begin{abstract}
This paper presents findings from an on-going international study of Early Childhood (EC) teachers' and children's use of Internet of Toys (loToys) to understand possibilities for developing children's cognitive capacities (e.g., creativity, inquiry, engineering design thinking). The study employed a Design Based Research (DBR) method, where teachers intentionally plan and deliver technologically constructed Science Technology Engineering and Mathematics (STEM) experiences for preschoolers. Using Australia as a case study, data collection involved participant observation of three teachers' and 17 children's technology constructed play experiences with robotic toys, littleBits electronic magnetic blocks, alongside pre and post semi-structured interviews with teachers and children's photo voice sessions were video recorded. Analysing the findings using embodied cognition theory showed that the teachers, although novice in their own technological pedagogical knowledge engaged children's play with the robotic toys, and co-learn with the children. Integration of STEM-focused playful experiences supported children's scientific inquiry, design thinking and creativity as well as vocabulary targeted at interdisciplinary STEM concepts. With the ever increasing focus on developing children's 21st century skills, this study recommends engineering habits of mind, creativity and inquiry dispositions should now be taken into account in teaching and learning situations with young children and to develop STEM engagement.
\end{abstract}

Keywords: scientific inquiry, early childhood, engineering design thinking, children's STEM engagement, creativity

\section{INTRODUCTION}

The recent shift to a greater societal reliance on technology has mandated that young children's educators emphasize the integration of technology as a play-based manipulative to tune into children's learning and cognitive engagement (Arnott, Palaiologou, \& Gray, 2018; Fleer, 2018; Kewalramani \& Havu-nuutinen, 2019; Sullivan \& Bers, 2016). It has been predicted that, due to our rapidly changing technological society, $65 \%$ of the children entering our schools today may have jobs as adults that do not yet exist (Davidson, 2011; Education Council, 2014). For example, as part of the $\$ 1.1$ billion National Innovation and Science Agenda, the Australian Government has allocated over \$64 million to fund early learning and school STEM initiatives under the Inspiring all Australians in Digital Literacy and STEM measure (Commonwealth of Australia, 2017). This includes Inspiring STEM Literacy (early learning initiatives around \$14 million).

Thus in this paper we report data from an ongoing longitudinal Internet of Toys (IoToys), henceforth referred to as Robotics toys focusing on Australia as case study. The study employed a Design Based Research (DBR) method (Jetnikoff, 2015), whereby teachers intentionally plan and deliver technologically constructed Science Technology Engineering and Mathematics (STEM) experiences for preschoolers. By presenting young children (age 3-5 year

(C) 2020 by the authors; licensee Modestum Ltd., UK. This article is an open access article distributed under the terms and conditions of the Creative Commons Attribution License (http://creativecommons.org/licenses/by/4.0/).

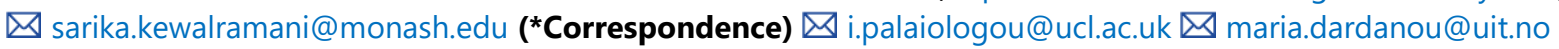




\section{Contribution of this paper to the literature}

- This study in unique in EC settings where young children tinker with technologies called littlebits magnetic blocks as play-based manipulatives which provides an additional channel for experimenting, activating real-world knowledge, and cultivating children's STEM-focused inquiry.

- This study contributes to the field of STEM-focused learning in the early years using IoToys/robotic toys where children are seen as being capable of demonstrating intelligent behavior indicators such as creative collaboration, procedural thinking, and resilience.

- This paper provides a nuanced understanding of how children's engagement in technology-enhanced inquiry activities augments children's engineering design skills and habits of mind. We recommend for EC curricula frameworks to urgently include the introduction of STEM interdisciplinary themes, to be addressed within and across learning and developmental outcomes and subject domains.

olds) authentic learning opportunities, the current study provides evidence to formulate integrated engineering and technology-based design thinking experiences for developing children's collaborative creativity, critical thinking and problem solving dispositions. The ' $T$ ' and ' $E$ ' in STEM is reframed not just as a subset of applied science, but as a significant integrated scientific activity in its own right, which is parallel, in teaching and learning to that of science inquiry skills (Peppler, Wohlwend, Thompson, Tan, \& Thomas, 2018; Sullivan \& Bers, 2016). This study provides a nuanced way of viewing STEM as an interdisciplinary approach, which serves as a collaborative and creative platform for building children's early science engagement and scientific inquiry. We report in this paper children's play specifically tinkering with 'littleBits' electronic blocks materials (www.littleBits.inc) as a part of our ongoing play with robotics toys. Children's play with the LittleBits technology resources was conducted as a pilot in the Australian preschool settings. We seek to answer the below research questions that are a small part of our overall longitudinal ongoing international study.

1. How does the introduction of littleBits and associated electronic magnetic blocks expand children's STEMfocused possibilities for play and creativity?

2. What kinds of critical thinking and interdisciplinary STEM concepts do children demonstrate?

\section{RATIONALE}

As a global need, this study is of particular importance in light of the recent Organization for Economic and Collaboration Development (OECD) research report, which highlights how young children's higher-order thinking, above and beyond content learning, can be fostered by STEM-supported pedagogical models (Kärkkäinen \& Vincent-Lancrin, 2013). Another issue in focus to act upon the understanding that EC educators agree upon - A sense of wonder arising from aesthetic STEM-based experiences should be the starting point for inquiry in EC education (Early Childhood Australia, 2018; National STEM School Education 2016-2026 Strategy, Australia, 2015; Marsh et al., 2017). The literature has risen questions on how early is "too early" to teach and learn about STEM concepts, and to what extend young children can engage with STEM concepts in a developmentally appropriate manner and through appropriate instruction.

Accordingly, EC educational research has seen considerable effort invested in understanding how STEMfocused interdisciplinary approaches can nurture 21st century learners' creativity, critical thinking and problem solving characteristics (Fleer, 2018; McDonald, \& Howell, 2012; Peppler et al., 2018; Sullivan \& Bers, 2016). As part of this necessity to indulge children in STEM learning experiences underpinning developmentally appropriate pedagogies, the current study utilizes littleBits as electronic building blocks that serves as a STEM solution (out of the emerging) for children's hands-on learning of science concepts. We report on how such tangible experiences where children become young creative engineers while being immersed into a technologically constructed learning environment using electronic magnetic blocks (littleBits), motors and sensors. Children as a part of collaboratively creating their artefacts become imaginative storytellers, share and present to their peers and parental community their personally meaningful projects that react in response to their environment (Bers, 2008; Bers, Seddighin, \& Sullivan, 2013; Elkin, Sullivan, \& Bers, 2016). Thus, making learning visible as also generating curiosity and inquiry dispositions within children's Technology and Engineering (T\&E) design thinking process.

\section{THEORETICAL PERSPECTIVE}

Cognition is not a phenomenon that can be solely studied while marginalizing the roles of body, world and action (Clark, 1999). Rooted within the seminal works of Piaget and Vygotskian theoretical approaches, the concept of embodied cognition is an interdisciplinary field of research (Thelen \& Smith, 1994; Vygotsky, 1978). Children's embodied cognitive capacities are shaped when they use their sensorimotor skills that make possible their basic 
interactions with the world (Piaget, 1952; Weiskopf, 2010). This study considers that children formulate intelligent behavior (e.g., collaborative creativity, design thinking and critical thinking processes) when immersed in a learning environment that is rich in manipulatives affording their T\&E design thinking processes.

Intelligent behavior comprises of children's experimental use of, for instance, robotic toys as manipulative 'agents' in a simulated controlled environment (Vygotsky, 1978). When children play with manipulatives such as robotic toys, sensors, motors, electronic magnetic blocks, we are embedding a stimulus-response situation in their learning environments. For example, to understand how the robot's battery (brain) controls the robot's movements and accomplish the tasks set by the children, a shift towards an embodied perspective is required (Clark, 1999). Children must learn to exploit the rich intrinsic dynamics of the system and as such develop intellectual behavior (Vygotsky, 1978). In the current study, children's embodied cognition is enabled by the technology-based manipulatives, which provide an additional channel during experimenting, activating real-world knowledge, and cultivating children's STEM-focused inquiry. Consequently allowing children's interdisciplinary STEM-focused learning, acquisition of language (e.g., scientific, mathematical), soft skills such as collaborative creativity, critical thinking and problem solving dispositions. Drawing upon embodied cognitive science theoretical approach (Clark, 1999), this paper aims to understand possibilities for children's intelligent behavior and cognitive capacities (Vygotsky, 1978) to engage in STEM-focused playful learning.

\section{TRENDS AND BENEFITS OF STEM-FOCUSED INQUIRY}

Past research has already told us that children as young as 3 years old can successfully build creative artefacts using construction wooden blocks, planks, Duplo and Lego kits, thus simultaneously familiarizing themselves with a range of engineering and science concepts (Bers, 2008; Fleer, 2010, 2015; Marsh, et al., 2017; Resnick, et al., 1998; Resnick, 2013). By doing this within their everyday EC settings, educators and children are unknowingly indulging in an interdisciplinary style of learning STEM concepts. More recently, when EC educators intentionally infuse the ' $T$ ' and ' $E$ ' within children's play, they provide opportunities for engineering and technology design thinking processes (Bers et al., 2013; Elkin et al., 2016; Sullivan \& Heffernan, 2016). For example, when Sullivan and Heffernan (2016) used Robotic Construction Kits (RCK) as computational manipulatives for learning in the STEM disciplines, made possible additional routes to learning through the provision of immediate feedback and the dual modes of representation unique to RCKs. Children's learning outcomes were made visible in terms of supporting their evolving problem solving abilities along a continuum, ranging from trial and error to embodied cognitive capacities.

Though an appropriate understanding of nature of STEM has been recommended by policy makers and EC education stakeholders as a significant component of multiliteracies (Marsh et al., 2017; Simoncini \& Lasen, 2018), understanding of nature of STEM is still in an amateur state. In an attempt to shed some light on this gap, Akerson, Buck, Donnelly, Nargund-Joshi, and Weiland (2011) demonstrated that children as young as kindergarten were developmentally capable of conceptualizing Nature of Science (NOS), when explicitly taught to them. Rarely do young children receive instruction in their preschool years that could contribute to better understandings of nature of STEM unless their teachers have had some kind of professional development for STEM-focused teaching and learning (Akerson et al., 2011; Peppler et al., 2018). This then begs the question "Are pre-schoolers simply not developmentally ready to conceptualize nature of STEM ideas, or whether educators' lack of understanding of nature of STEM needs explicit attention?" Our study aims to bridge the gap by providing children opportunities for STEM-focused inquiry learning through the creation of projects that can move around and respond to the environment through electronic manipulatives. Building on the works of Bers (2008) and Peppler et al. (2018), our study provides additional insights into understanding how through an interdisciplinary STEM learning approach and by providing design affordances and interfaces specifically developed for young learners, children's creativity really takes off. As Marsh et al. (2017) rightly concur creativity is not disciplinary-specific, and creative expression in makerspaces for example, can cross, and/ or integrate, STEM with the arts and humanities. The project differs from previous studies by documenting and showcasing children's understanding of interdisciplinary STEM concepts as well as informing an understanding of children's intelligent behaviour which is made visible through their creativity and competencies as multimodal designers. In order to make technology and engineering instruction most useful for early childhood classrooms, we use DBR to intentionally plan open-ended STEMfocused activities that offer children design thinking affordances, specifically developed for young learners. A five step planning process was adapted from (Kewalramani \& Havu-nuutinen, 2019) study concerning the essential features of teachers' planning for developing children's STEM-focused inquiry and creativity.

\section{THE STUDY}

As mentioned above this paper stems from a longitudinal study that examines the use of IoToys at home and EC education. The project began in 2018 with Greece, England, Scotland and Northern Ireland (UK). Australia and 


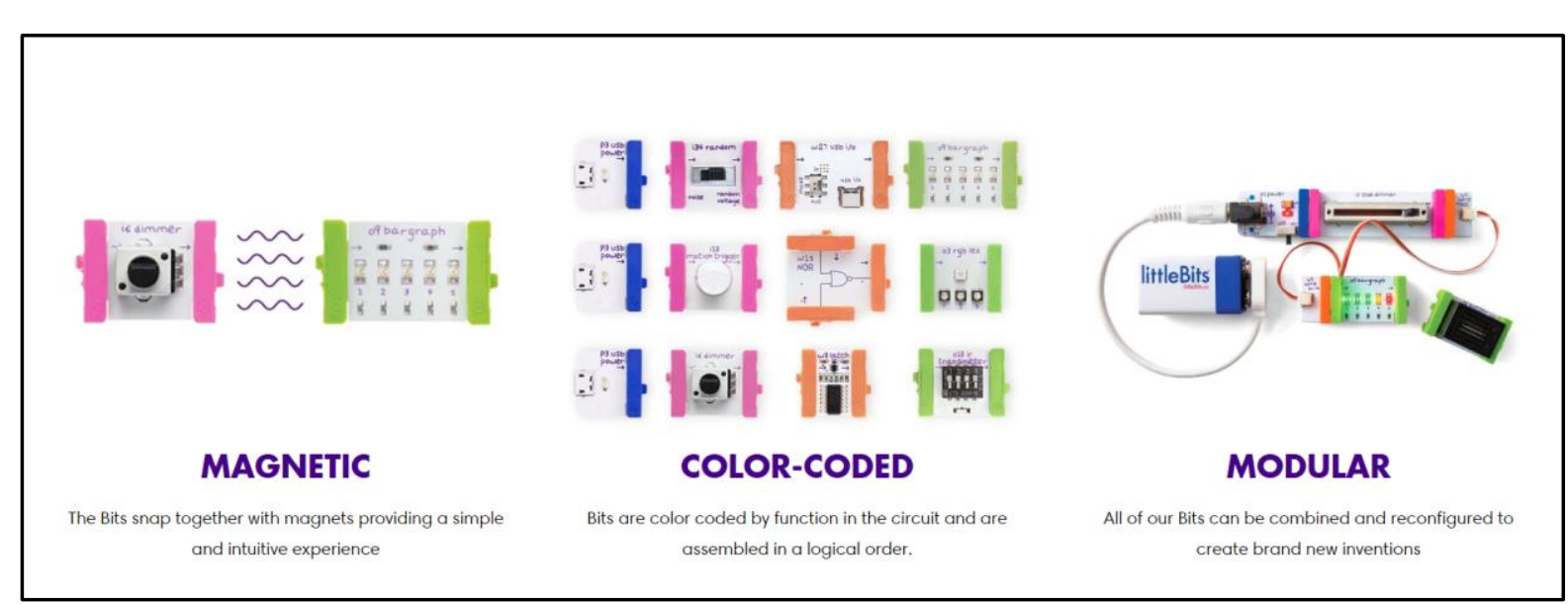

Figure 1. littleBits components and how do they work

Norway being the participant countries since start of 2019. The project employed a multi method approach to be culturally relevant to each country. The case study described in this paper was designed to utilize littleBits which are electronic building magnetic blocks that snap together to "Make Something That Does Something" (littleBits electronics Inc., 2017). To the best of our knowledge to date, littleBits kit materials are yet to be used in a preschool (with children age 4-5 years old) learning environment. We provided children only with age appropriate littleBits materials to create their innovative solutions. For example, the electronic blocks allowed children to create simple inventions such as providing a source of light and sound sensors, and more complex inventions for those who needed further challenges, such as creating a mobile robotic arm, hammer, electric fans, self-driving vehicle to perform set tasks and design solutions. LittleBits can be purchased as individual kits or within different types of specific kits. The kit used for this project was called as Space Rover Inventor Kit. As seen in Figure 1, the anatomy of littleBits is based on color-coded bits. The blue bit represents the power source and connects to a 9-volt battery with a battery cable that is included. Pink bits represent input bits, allowing the creator to control the circuit. In this project, children used a dimmer, switch and a button. Green bits represent output bits and LEDs generating light (flashing or continuous), servos and DC motors causing motion such as used for creating fans, movable robotic arms or buzzers creating beep beep sounds for vehicles. Interestingly, the magnets are always right - you can't snap them together the wrong way. And this allows for children's self-problem solving without having an adult to give specific instructions for use.

In addition, we also provided the children with littleBits accessories such as the motorMate, which makes it easy to attach LEGO® axles, and lots of other art craft materials to the green bit, the DC motor (littleBits Inc., 2017). The mechanical arm was another accessory we provided that attaches to both the servo hub and the DC motor shaft, and offers lots of leverage for pushing, pulling, and throwing objects. This enabled children's creation of mobile robotic arms. Lastly, wheels used as an accessory provided children for making bots, cars, and all sorts of spinning inventions.

\section{METHODS, CONTEXT AND ETHICS}

Briefly, in Australia, preschool education is provided by both private and public sectors, which include long day care centres, sessional and community kindergartens, and Early Learning Centres (ELC) affiliated with private primary and secondary schools. The Early Years Learning Framework Australia's (EYLFA) Belonging, Being $\mathcal{E}$ Becoming framework supports all professionals curriculum planning who work with children aged 0-8 (Department of Education and Employment Workplace Relations, DEEWR, 2009).

The case study (piloted in Australia) discussed here investigates the below two research questions:

1. How does the introduction of littleBits and associated electronic magnetic blocks expand children's STEMfocused possibilities for play and creativity?

2. What kinds of critical thinking and interdisciplinary STEM concepts do children demonstrate?

Participants involved three educators (one Bachelor of early childhood trained teacher, a co-educator and the ELC director from one ELC affiliated with a private primary and secondary school) and 17 children's play with the littleBits electronic materials to investigate research questions mentioned. Design Based Research (DBR) approach was employed, which is apt for small scale educational research projects involving collaboration between educators and children, and the researchers (Jetnikoff, 2015). The five steps within the DBR approach were adapted from Kewalramani and Havu-nuutinen (2019) study concerning the essential features for developing children's STEM- 
focused inquiry and creativity - planning; scaffolding; building children's inquiry skills; teacher-child and peerpeer interactions; and, assessment/review of children's STEM-focused learning. By employing these pedagogical steps, we extend the Pre- and Post-Whole Class Discussions analytical techniques employed by Peppler et al.'s (2018) study involving children's circuitry learning and science concepts.

In the context of this study, it was crucial to be in proximity to reality, observe the educators' practices, instructions and interactions as well as hear the viewpoints of the educators and children during their play with littleBits kits. Hence, we choose a naturalistic study design, wherein the children's play with the littleBits together with the educators and researchers was examined in a natural and lived setting as a participatory research (Denzin \& Lincoln, 2011; Groundwater-Smith, Dockett, \& Bottrell, 2014). Participants involved 17 children and 3 educators in their ELC settings with video observations collected for four weeks (the larger ongoing project has 8+ weeks of children's play with robotics toys). What we report in this paper is where children specifically tinkered with only littleBits materials as a part of their ongoing play with robotics toys. A total of 10 hours of digital video data were collected. Other forms of data collection included teachers' weekly reflection journals along with field notes, photo voice conversations with 9 children (1 hour of data) and educators during and after each session's weekly play with littleBits in their everyday EC settings. We particularly pay attention to how the children participate, experiment and shape their own STEM-focused learning during play with littleBits. Field notes were used to document the context, routines and procedures, alongside of the rapport building with the children. In addition, towards the end of the four week period, the collected documentation included photographs of children's samples of work, artefacts, children's constructed models and 30 minutes focus group with the three educators.

Children's participation was voluntary; parents were advised that children's lack of engagement was a reasonable finding and not to force participation. The research project was approved by the Monash University Human Research Ethics Committee and followed all the protocols inherent to the conduct of research in an ethical manner. Ethical procedures were ensured to seek educators, parental and children consent, being mindful that the observation sessions and conversations with children and educators were not intrusive. We ensured that the observation sessions suited the educators' pedagogical needs, opinions and respected their professional knowledge and experiences with the use of types of technologies involved in the project. Parental consent was sought for their children to participate in the project. Pseudonyms have been used for the ELC settings and their respective educators and children.

\section{PEDAGOGICAL STEPS}

The ELC visits were made at a frequency of one day per week for a duration of two-hours (total of four weeks for littleBits play). The first author together with the research assistant made these site visits. Prior to starting the project, the first author made two visits to give a brief introduction of the use of various technologies and the littleBits involved in the project, henceforth playing an alternated role of an instructional leader and instructional support. The school visits reflected the pedagogical steps (Table 1) of implementation of the littleBits program that were co-created by the researchers, educators and children, thus employing a child-centred approach. The five pedagogical steps were: (1) planning, (2) scaffolding, (3) building children's inquiry skills, (4) teacher-child and peer-peer interactions, and, (5) assessment/review of children's STEM-focused learning.

\section{DATA ANALYSIS}

Data analysis was conducted using the pedagogical step design (Table 1) underpinning the study's theoretical framework of children's conceptualization of intelligent behavior and embodied cognition (Clark, 1999; Vygotsky, 1978). These steps helped in mapping children's play with the littleBits throughout the program to understand their development of STEM-focused interdisciplinary learning, and intelligent behavior involving creativity and critical thinking processes. The amount of scaffolding and support provided to both educators and children at the start of the project was quite high, where each step of using the littleBits components was modelled (McDonald \& Howell, 2012). This was intentional as the language, connections and mechanics of the magnetic blocks were being learned. However, from step 3 onwards (see Table 1), children took off with their own inquiry and via peer interactions figured out how the connections work and immersed themselves into developing their own creative ideas and solutions for their robot city.

Units of analysis were the video recorded classroom conversations with the educators and amongst the children, photo voice conversations with children, children's constructed artefacts along with the educators interviews. The 10-h footage was analyzed using Vosaic (https://vosaic.com/), a video analysis software. These conversations were used to track the emergence of meanings across the conversation rather than to attribute utterances to individuals, since children were seen to be co-constructing and contributing to classroom knowledge (Peppler et al., 2018). Based on Hedegaard's (2008) three levels of analysis, first, all video recordings and conversations with educators and children were watched and common-sense interpretation was made, taking different perspectives 
Table 1. Pedagogical steps for planning

\begin{tabular}{ll}
\hline Step & Activity/Actions \\
\hline Planning & The overall play with the robotic toys and littleBits was co-created by the researchers, educators \\
and children, thus employing a child-centred approach. LittleBits materials were not introduced \\
intentionally. It was an inquiry process driven by the children wanting to build objects for their \\
robot city.
\end{tabular}

including children and educators within their natural settings and play environment. Secondly, situated practice interpretation and sense making of the children's and educators conversations, types of interactions and emerging thinking during play were deciphered. Lastly, through a systematic analysis of the implementation of the littleBits play, themes were deduced that achieve the research aims, keeping in mind the theoretical understanding of children's intelligent behavior, embodied cognitive development and STEM-focused learning.

Taking into account of the full richness of interpretation of the children's thoughts, feelings, experiences and interactions, the data is presented in the form several short vignettes of children's construction of artefacts using littleBits materials and debugging processes working through various solutions to identify and fix a non-working component (Clandinin, 2007; Peppler et al., 2018). Within the vignettes, we flesh out and make meaning of not only what was spoken, but also of the meaning behind the educators and children's words, gestures, facial expressions, actions and what remained unspoken. We present the findings featuring nine children with high engagement and persistence. These vignettes are illustrative examples of specific STEM-focused concepts in action we witnessed throughout the classrooms. Each example was chosen to illuminate a particular STEM concept important to understanding the interdisciplinary nature of STEM learning that occurred during littleBits play.

While we describe these vignettes as illustrative rather than representative, the conversations and actions are not altogether different from what was seen across all the children (Peppler et al., 2018). The educators flagged early enough that those nine children had high interests in science-based activity learning and design thinking and would benefit the best from the learning that would follow after their experimentation with littleBits. As such, for further analyses due to the potential for a high likelihood of illuminating and exhibiting exemplar collaborative, creative and intelligent behavior moments, data is presented as two broad themes from the learning that happened with the focal group of the nine children. Although, findings presented here reveals the focus on the overall littleBits play activities in the ELC classroom. For example, we tagged instances with the specific STEM-focused concepts that were being engaged with during conversations (e.g., electricity, circuits, coding, connections, solar energy, solar panels and wind power). Such terminology was grouped under children's building of science vocabulary, scientific literacy, STEM-focused concepts). We termed these as a broad theme of 'emergent learning about STEMfocused concepts'. Exemplars of collaboration, knowledge construction, creative design solutions, critical thinking, debugging, problem solving were formulated the theme 'intelligent behavior moments'. 


\section{RESULTS}

\section{Emergent Learning about STEM-focused Concepts}

Children's usage of STEM-based language, specifically scientific literacy skills was positive. While constructing artefacts for their robot city, children conversed with each other using a range of new words associated with STEMfocused learning such as building solar panels, needing power and energy using batteries, electricity, including complex words such as wire connections, magnet connections, and circuits. Through series of questions, the teacher scaffolded children's understanding of what connections can do. During the first play session, the teachers and the researcher collaboratively scaffolded children's understanding of the parts of the littleBits and the functioning of the components. The below vignette demonstrates how children were explicitly supported to learn the mechanics and engage in connectivity processes, whilst debugging their circuits. It seemed that this was simulating and following an induction phase of the engineering design process.

Teacher (T): Can we try making it work? [Turning to Willy's circuit and pointing at the LEDs] I wonder why the lights are becoming so dim?

Willy: On the slider.

T: On the slider! Wow! So what are you trying to control? [As pointing to all of the LEDs, saying "too much power" and suggests making the circuit smaller].

Mia: It's not working this green one! [Reconnects old circuit using all pink pieces].

Mia: Look at mine! Now is on!

T: Yes, now we've got traffic lights in the robot city. [Pointing to LEDs] We've got red, yellow and green for our traffic lights.

The following vignette is an excerpt from the video data about children presenting their created circuit and using littleBits magnet blocks for building horns for their bus and traffic lights for their robot city.

Teacher (T): How it can be used in the city?

Eddie: A horn.

Jack adds on: A horn in the bus to drive it.

Teacher then repeats this sequence of questions with the fan in their circuit.

T: How does it work?

Willy: Because it has the battery on?

$\mathrm{T}$ : What does the battery give us?

Willy: Power

The teacher moved on to the next group to share their findings of the littleBits experimentation.

T: So, Pooja and Ari could you share what you did please.

Pooja: Oh, this little switch makes it

T: Powers it on, did you say? [teacher provides support in children's understanding of the switch giving power to work]

T: And what's happening on the end with the white one? [Points to motor] It's moving? What's that one moving? [Ari picks up motor]

$\mathrm{T}$ : Yes, that one there!

Ari: It's spinning around because it's plugged into that [points to the motor circuit piece]

T: Would you like to keep this in your robot city? [Children nod].

Using inquiry questions such as what and how, the teacher attempted to arouse children's inquisitiveness for exploration and discovery to gauge their understanding of how they made the horns work and make beeping sounds. Children's learning of scientific language was put into context when they were exposed to authentic real life examples such as where they have seen solar panels, electric fans, horns on the bus. The teacher developed children's thinking process to experiment and test whether their prototype (electric fans, horns, moving wheels using sensors and motors) were working. Children started testing their knowledge by trialling, experimenting to build functioning circuits and achieve their goals for the robot city. 


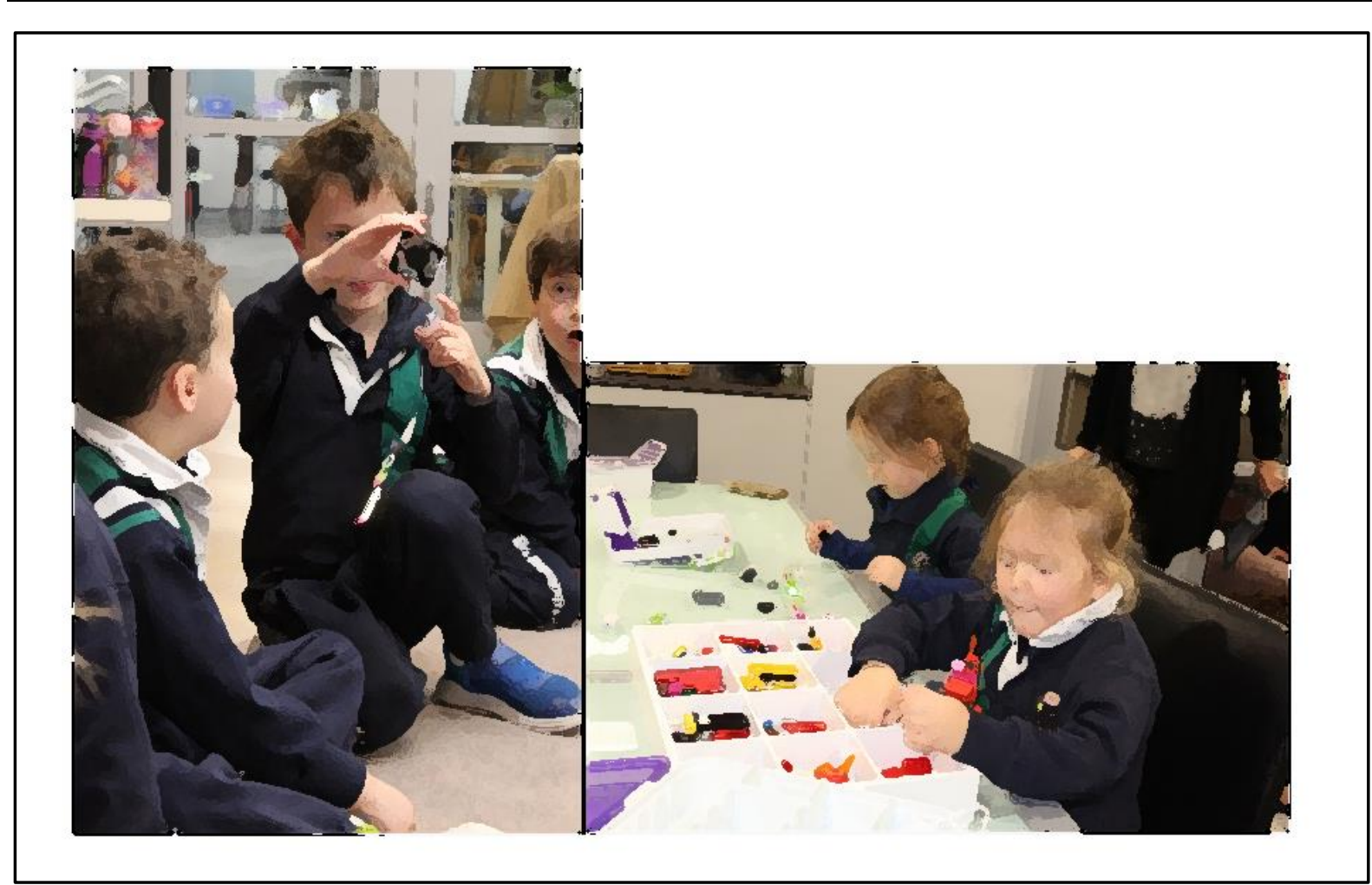

Figure 2. Children making fans and traffic lights for their robot city

As another provocation, the educators together with the first author first built a moving robot using the littleBits magnetic blocks in the Spacerover inventor kit (https: / / littlebitsinaustralia.com.au/littlebits-space-rover-inventorkit.html). Since the children were exploring and role playing during drama sessions about how solar panels work, we introduced the children to the Spacerover robot, dismantled all the parts and built it again in front of the children. Because the Spacerover robot had solar panels and this kick started the conversations about how solar panels work and what kinds of energy they need. Children's inquiry thinking was sparked using questions such as "How will be Spacerover robot move?"; What kind of jobs will you like the Spacerover do for you?"; Where have you seen solar panels and how they work?". We then allowed the children to tinker with the littleBits magnetic blocks to create their own artefacts and demonstrate their ideas and solutions. Below is a vignette of reflective conversations about children's usage of STEM-focused concepts and vocabulary while presenting their artefacts to their peers:

T: Great, what did you make Eddie and Willy? Do you want to show everyone what is does please?

[Edward turns motorised wheel on]

T: Woah! Now look what Eddie is doing! Can you explain what you had to do?

[Willy turns the 'var' button to see if the wheel wants to go the other way around]

Willy: It swaps, lets see. [Puts wheel on ground] It's going that way [Eddie begins to flick switch].

[Children go Aaah]

Willy: Can I switch it?

T: Eddie, so what does a slider do, I've never seen that before?

Willy: It can move the thing. When you slide it that way it stops and when you move that way it goes.

$\mathrm{T}$ : So it sort of controls it does it?

Willy: Yes.

[Eddie slows motor]

T: Ok, so it's slower and then what happens if you push it up and up and up?

Willy: It goes fast speed. 


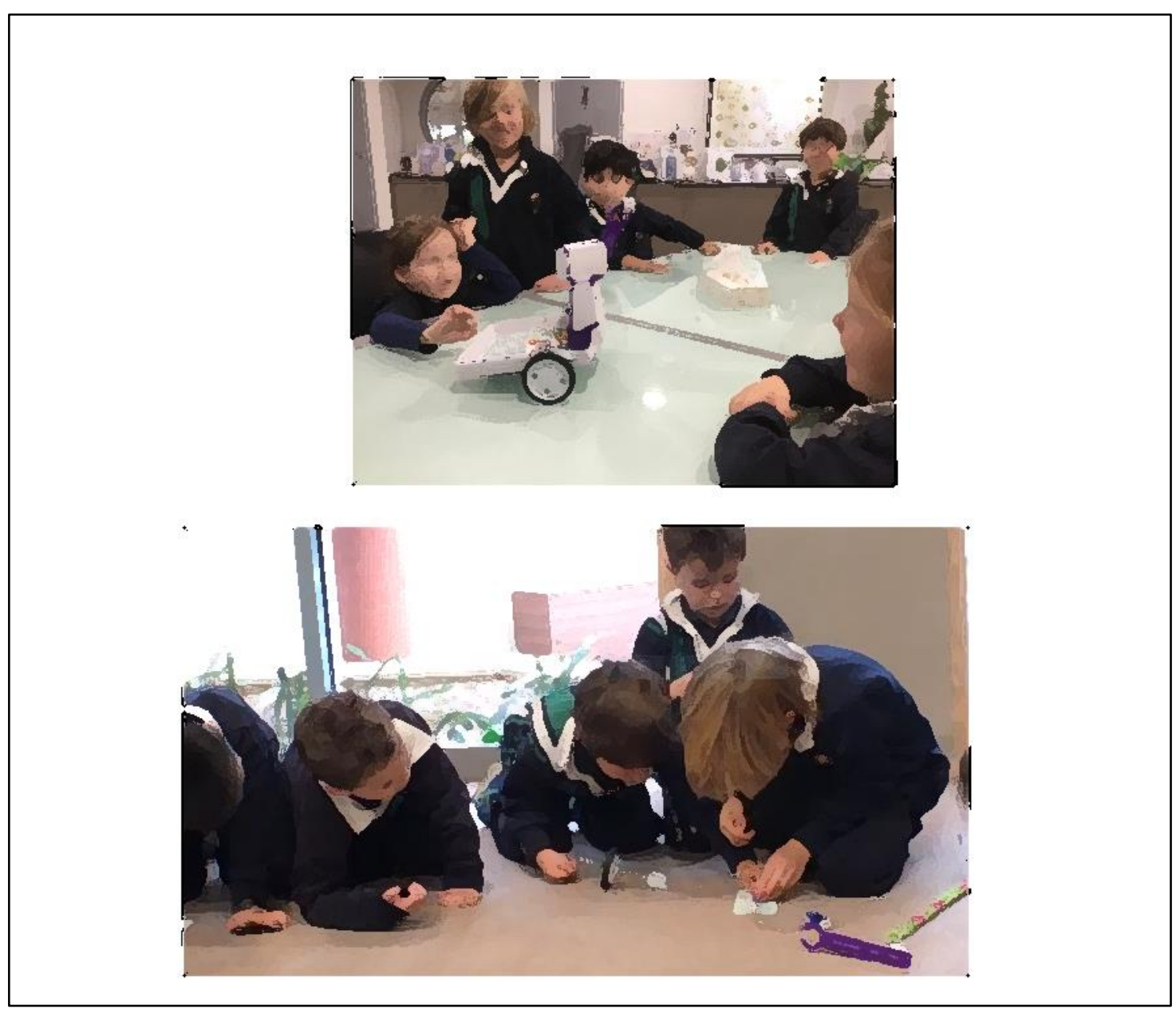

Figure 3. Play with the spacerover robot and children's construction of moving wheels

While reflecting upon children's littleBits play and explorations, the three educators were in harmony with respect to the degree of improvement in children's scientific vocabulary. Libby, the ELC director, claimed "this exploration has provoked children's vocabulary very much. The range of words used have been amazing which links to what they have observed and understood". This claim was supported by the teacher Carla, "Words such as coding, energy, electricity, circuit, connections, and power wouldn't have been used otherwise if littleBits wasn't exposed to the children". The teachers' comments related back to how children gained confidence in using scientific language and engineering specific terminologies after being exposed to the magic of the Spacerover robot and the electronic blocks.

\section{Cognitive Engagement}

In another reflective conversation, the teacher probed children's thinking to gauge how they not only problem solve, but also problem finding if their circuits did not function properly. Through trial and error, children used their gained experimental knowledge to further engineer their artefacts. Together children made goals of building electronic circuit designs such as buzzers (producing sound using sound sensors) and electric fans.

T: What would we do with it if it's in the robot city? How would we use it?

Jonty: They could drive it.

T: They could drive it. It might need wheels to drive it. OK, so John and Tyson, what have you made?

John: Ours doesn't work.

T: Oh, it's not working? Was it working? Did you have it working?

John: Yes, only when you take off this [takes off one piece] and leave one thing. [Buzzer sounds]

$\mathrm{T}$ : Oh, it looks like it's working now. The light is on. 


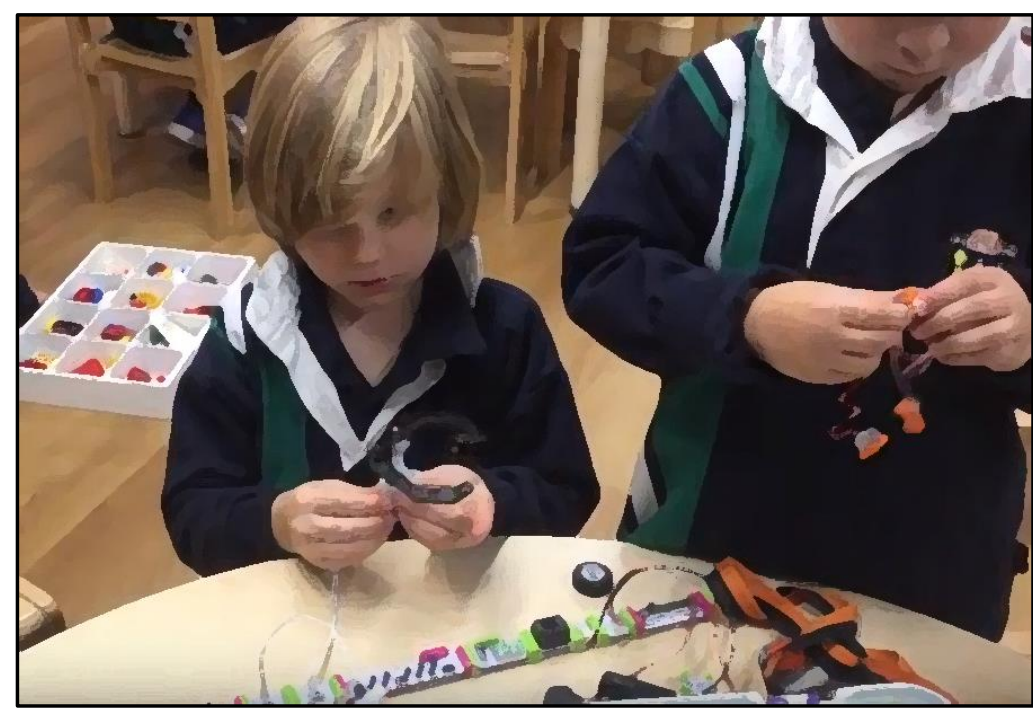

Figure 4. Children constructing motorized wheels and objects for their robot city

John: Yes, but when you put on one thing [adds another piece], it stops [buzzer stops]. Only one thing can handle it.

T: So it can only do one thing at a time? Is that your buzzer making that noise? [John nods]. How do you make it stop? [John switches switch]. Oh! I didn't know that that was buzzing. Great! And what's this one do Tyson? [Points to other circuit]

Tyson: This one spins. But this one doesn't spin because I'm not sure how it spins.

T: Ok, show us how the other one spins. Switch it on, is it on? Can you make it work? Do you need the battery power? How are you going to make it work?

John: It doesn't work, only when there is one thing left, it works.

Other children interrogate and one child says: I think the battery will help it work.

Jonty: No it won't. [shakes head]

T: Why don't you think the battery will help Jonty?

Jonty: Because there's no plug in.

T: oh, does it need to plug in?

Jonty: There has to be a square thing.

T: Which square one?

Jonty: Where you open it and put the batteries in.

In this way, children explored elements of logical sequencing to make their desired objects work. And if the prototype did not work then be able to find the problem. In one of the exploration processes, Jonty was making a circuit with some led lights, a fan and a speaker. Jack was making a motor with a lego wheel attached. Jonty places grey Lego cylinder on top of spinning fan, it rotates around and around with the fan. Teacher comes and observes.

Tyson: [To teacher] Then we make a speaker. [He slides the slider up and down]

T: I can hear it. Aha. How did you make that one go Tyson?

Tyson: [pointing to turning fan] this one is making the sound and this one [points to motor] is turning the wheels.

Teacher: Aha! Good Job!

Jack uses his motorized wheel to turn a fan that is not on.

Jack: Guys! Look at what I can do with this fan!

Willy: Hey guys, do you want some wind in your hair? [Picks up fan]. Laughs.

In another reflective and sharing conversations, the below vignette shows how children generated movement of the parts, signals such as sound and light using sensors (keyboard sensor) and connecting this knowledge to their everyday environment experiences. This is how children made sense of cause and effect when the sound is produced. 
T: Go. I want to hear it. [Willy presses keyboard] Oh! You have to listen very carefully. It's a different noise to before. I wonder why it's different? Listen!

Pooja: I think it's the sound of the bubble wrap.

T: A bubble wrap sound? What do you think Laura?

Laura: It's like fireworks.

T: Good one Laura!

John: It's like drums!

T: Like drums?

R: What are you making that sound from? What's the bit called?

Willy: Piano

T: Ah, that's cool.

Such experimentation techniques simulate a typical engineering design process which was achieved by integrating T\&E play-based activities. The best way for children to learn is through trial and error where they organically demonstrate intelligent behavior characteristics such as manipulating and testing objects to construct knowledge about how the world around them works. Children used their own logical understanding as they were not explicitly taught how to make circuits. They developed shared understandings and confidence through peer and teachers' co-collaboration.

While reflecting upon children's littleBits play and explorations, the three educators agreed that learning doesn't happen in silos in EC. Following children's interests is at the core of their planning and hence engagement with the littleBits activities was an eye opener for them as well as the children to construct knowledge together. Libby exclaimed that "this whole journey with the robotic toys, Spacerover robot and the littleBits was the stimulus that enabled children to work together and extended their learning. Making the fans, wheels for their robots spin and connect things how they work expanded their thinking. Children now want to make a battery shop in their robot city so if the robots ran out of energy can charge their batteries". The teachers agreement on children being given the opportunity to produce electricity, make their prototypes work and achieve their goals extended their learning and made their thinking visible. Children drew on their 'new-found' knowledge and engineering design skills of building working models/ prototypes to construct further artefacts for their robot city.

\section{DISCUSSION AND CONCLUSIONS}

Our findings have shown that T\&E play activities exposed to the children fostered peer collaboration along with teachers as co-collaborators making meaning of the interdisciplinary STEM concepts. This then builds a community of learners constructing STEM-focused knowledge, skills and dispositions. Children taking different roles during the littleBits play, problem finding and debugging solutions to make their circuit work, thus portraying that they can problem solve together. Those children who are more curious are persistent in making the circuits work, thus taking the role of the leader and offering plausible solutions to other children in the group (Bers, 2008; Bers et al., 2013; Elkin et al., 2016; Sullivan \& Bers, 2016). Such peer teaching and collaboration is a significant indicator for cognitive development that emerges through playful learning rather that directed teaching.

As was shown in the examples of the data above, when children debug the circuit to make the horns beep, the fans or wheels move using the appropriate parts, recreate solutions to suit their objective, they demonstrate resilience. Getting over the feeling of failure of circuits which may not work and attempting to problem solve is another indicator of intelligent behavior, which researchers call as emotional intelligence (Dewey, 2011; Mayer \& Salovey, 1995; Sternberg, 1996). These are lifelong habits important for $21^{\text {st }}$ century learners and future workforce (Davidson, 2011; Education Council, 2015). Besides, integrated T\&E experiences expose children to abstract scientific and everyday concepts such as power, energy, and electricity. Although the educators and children may not be interested in focusing on the scientific vocabulary acquisition and usage, they still demonstrate intelligent behavioral indicators such as process skills including the procedure to make a circuit work (procedural knowledge). As such, learning by doing is an important educational philosophy which is to be practiced for young children right from early years (Dewey, 2011; McDonald \& Howell, 2012).

As research has shown for effective learning educators should make learning real, relevant and rewarding (e.g. Dewey, 2011). Our study argues that EC professionals should now see and understand that technology offers potentialities and multitude ways of thinking, exploring and doing with young children especially when it comes to abstract concepts as in the case of STEM. Extending Bers et al.'s (2013) and Peppler's (2018) studies, this study further contributes to work in the field of STEM-focused learning in the early years using IoToys/robotic toys where children are seen as being capable of demonstrating intelligent behavior indicators such as creative collaboration, procedural thinking, resilience, and adapting strategies to overcome failure. Such characteristics 
should be harnessed right from early years where children are capable of displaying powerful ideas via T\&E experiences, which aids in cognitive development (Clark, 1999; Sullivan \& Bers, 2016). While there was an agreement among the educators of this study, that STEM-focused learning in early childhood settings is interdisciplinary, it is time to now practice and implement STEM education as a gateway to preparing young children for formal schooling and consequent future careers in engineering. Although technological fluency, scientific literacy or STEM-based or engineering design literacies are not seen an important learning and developmental curricula outcomes, T\&E play based experiences does hone into children's interpersonal skills and future readiness for primary schooling. Our study suggests that children's engagement in technology-enhanced inquiry activities that occur in informal and formal settings when supported through age-appropriate pedagogies and steps augments children's metacognitive and social knowledge construction (Arnott et al., 2018; Sullivan \& Bers, 2016). Henceforth, developing children's engineering design skills and habits of mind (Lucas \& Hanson, 2014; Simoncini \& Lasen, 2018).

\section{LIMITATIONS AND FUTURE DIRECTIONS}

This Australian pilot study, although part of a larger international study, collected limited data from one preschool. The four weeks of T\&E play experiences with littleBits was too short to allow the children to learn more advanced interdisciplinary STEM-focused concepts. Children and educators were only able to experiment with one Spacerover kit and children's play could have extended further by constructing their own mobile robots and controlling them using littleBits apps and IoToys using hybrid interfaces. Further larger scale and longitudinal studies should consider mixed-methods approach (both children's and educator interviews together with surveys) to get a wholesome picture of the impact on children's STEM-focused conceptual understanding, intelligent behavior characteristics and engineering design thinking skills.

Further implications of this study lies in EC stakeholder and media attention in strengthening EC educators' capacities to understand the interdisciplinary nature of STEM (Akerson et al., 2011) and nurture children's STEM learning. Future research agenda should also align with a curriculum emphasis on harnessing children's intelligent behavior and engineering habits of mind (Lucas \& Hanson, 2014; Simoncini \& Lasen, 2018). In a 2017 report entitled, The New Work Mindset (Foundation for Young Australians), an analysis of over 2.7 million job advertisements revealed seven job clusters in the Australian economy: the generators, artisans, carers, coordinators, informers, technologists and designers (Education Council, 2015). As such, curriculum needs to provide educators with professional development and tangible resources, and employing integrated pedagogies including exemplars of T\&E inquiry-based experiences so they feel confident and armed to foster these skills in young children.

Recommendations for EC curricula frameworks include the introduction of interdisciplinary themes, to be addressed within and across learning and developmental outcomes and subject domains. These could contribute to make connections stronger for educators to understand and plan for children's acquisition of 21st century skills via STEM-based inquiry and explorations (Voogt \& Roblin, 2012). With the ever increasing focus on the 4 C's of the 21st century skills, we recommend engineering habits of mind (Simoncini \& Lasen, 2018; Sullivan \& Bers, 2016) creativity and inquiry dispositions should now be taken into account in teaching and learning situations. This is because that at best, interdisciplinary STEM education serves to provide diverse opportunities for creative learning activities with for example, IoToys/robotic toys (Arnott et al., 2018) and high order thinking abilities among children.

\section{REFERENCES}

Akerson, V.L., Buck, G.A., Donnelly, L.A., Joshi, N., \& Weiland, I. (2011). The importance of teaching and learning Nature of Science in the Early Childhood Years. Journal of Science Education and Technology, 20(537). https://doi.org/10.1007/s10956-011-9312-5

Arnott, L., Palaiologou, I., \& Gray, C. (2018). Digital devices, internet - enabled toys and digital games: The changing nature of young children's learning ecologies, experiences and pedagogies. British Journal of Educational Technology, 49(5), 803-806. https:/ / doi.org/10.1111/bjet.12676

Australian Government Department of Education and Training. (2018). Through growth to achievement: Report of the review to achieve educational excellence in Australian schools. Retrieved from https:// docs.education.gov.au/node/50516

Bers, M. U. (2008). Blocks to robots: Learning with technology in the early childhood classroom. New York: Teachers College Press.

Bers, M. U., Seddighin, S., \& Sullivan, A. (2013). Ready for robotics: Bringing together the T and E of STEM in early childhood teacher education. Journal of Technology and Teacher Education, 21(3), 355-377. Retrieved from https:/ / pdfs.semanticscholar.org/3850/1e91278c089369396e99f723701f7be036b8.pdf 
Clandinin, D. J. (Ed.). (2007). Handbook of narrative inquiry: Mapping a methodology. Thousand Oaks, CA: Sage Publications. https:// doi.org/10.4135/9781452226552

Clark, A. (1999). An Embodied Cognitive Science? Trends in Cognitive Sciences, 3(9), $345-351$. https:/ / doi.org/10.1016/s1364-6613(99)01361-3

Commonwealth of Australia. (2017). National innovation and science agenda. Australian Government. Retrieved from https:/ / www.education.gov.au/national-innovation-and-science-agenda

Davidson, C. N. (2011). Now you see it: How the brain science of attention will transform the way we live, work, and learn. New York, NY: Viking.

Denzin, N. K., \& Lincoln, Y. S. (2011). The SAGE handbook of qualitative research (4th ed.). Thousand Oaks, CA: Sage.

Department of Education and Employment Workplace Relations. (2009). Early Years Learning and Framework Australia: Belonging, Being \& Becoming. Retrieved from https://docs.education.gov.au/system/files/doc/ other/belonging_being_and_becoming_the_early_years_learning_framework_for_australia._v5_docx.pdf

Dewey, J. (2011). Democracy and Education. Milton Keynes: Simon and Brown.

Early Childhood Australia. (2018). Statement on young children and digital technologies. Retrieved from http:/ / www. earlychildhoodaustralia.org.au/our-work/submissions-statements/eca-statement-young-children-digitaltechnologies/

Education Council. (2015). National STEM School Education Strategy 2016-2026. Canberra: Australian Government. Retrieved from http://www.educationcouncil.edu.au/site/DefaultSite/filesystem/documents/National \%20STEM\%20School\%20Education \%20Strategy.pdf

Elkin, M., Sullivan, A., \& Bers, M. U. (2016). Programming with the KIBO robotics kit in preschool classrooms. Computers in the Schools, 33(3), 169-186. https:/ / doi.org/10.1080/07380569.2016.1216251

Fleer, M. (2010). Early learning and development: Cultural historical concepts in play. Cambridge: Cambridge University Press. https:/ / doi.org/10.1017/CBO9780511844836

Fleer, M. (2015). Science for children. Cambridge: Cambridge University Press. https://doi.org/10.1111/chso.12095

Fleer, M. (2018). Digital animation: New conditions for children's development in play - based setting. British Journal of Educational Technology, 49(5), 943-958. https:/ / doi.org/10.1111/bjet.12637

Groundwater-Smith, S., Dockett, S., \& Bottrell, D. (2014). Participatory Research with Children and Young People. London: Sage. https:/ / doi.org/10.4135/9781473910751

Hedegaard, M. (2008). Principles for interpreting research protocols. In M. Hedegaard, M. Fleer, J. Bang, \& P. Hviid (Eds.), Studying children: A cultural-historical approach (pp. 46-64). Maidenhead/New York: Open University Press.

Jetnikoff, A. (2015). Design based research methodology for teaching with technology in English [online]. English in Australia, 50(3), 56-60. Retrieved from https:// eprints.qut.edu.au/93742/11/93742.pdf

Kärkkäinen, K., \& Vincent-Lancrin, S. (2013). Sparking innovation in STEM education with technology and collaboration: A case study of the HP Catalyst Initiative. OECD Education Working Papers, No. 91. OECD Publishing. https://doi.org/10.1787/5k480sj9k442-en

Kewalramani, S., Havu-Nuutinen, S. (2019). Preschool teachers' beliefs and pedagogical practices in the integration of technology: A case for engaging young children in scientific inquiry. Eurasia Journal of Mathematics, Science and Technology Education, 15(12). https://doi.org/10.29333/ ejmste/109949

littleBits electronics Inc. (2017). Kits, Curriculum, Community. Retrieved from https:/ littlebits.com/

Lucas, B., \& Hanson, J. (2014). Thinking like an engineer: Using engineering habits of mind and signature pedagogies to redesign engineering education. International Journal of Engineering Pedagogy, 6(2), 4-13. https:/ / doi.org/10.3991/ijep.v6i2.5366

Marsh, J., Kumpulainen, K., Nisha, B., Velicu, A., Blum-Ross, A., Hyatt, D., ..... Thorsteinsson, G. (2017) Makerspaces in the Early Years: A Literature Review. University of Sheffield: MakEY Project. Retrieved from http:/ / makeyproject.eu/wp-content/uploads/2017/02/Makey_Literature_Review.pdf

Mayer, J. D., \& Salovey, P. (1995). Emotional intelligence and the construction and regulation of feelings. Applied and Preventive Psychology, 4, 197-208. https:/ / doi.org/10.1016/S0962-1849(05)80058-7

McDonald, S., \& Howell, J. (2012). Watching, creating and achieving: Creative technologies as a conduit for learning in the early years. British Journal of Educational Technology, 43(4), 641-651. https://doi.org/10.1111/j.14678535.2011.01231.x 
Peppler, K., Wohlwend, K., Thompson, N., Tan, V., \& Thomas, A. (2019). Squishing circuits: Circuitry learning with electronics and playdough in Early Childhood. Journal of Science Education and Technology, 28(2), 118-132. https:/ / doi.org/10.1007/s10956-018-9752-2 10.1007/s10956-018-9752-2

Piaget, J. (1952). The Origins of Intelligence in Children. New York, NY: W.W. Norton \& Co. https:/ / doi.org/10.1037/11494-000

Resnick, M. (2013). Learn to Code, Code to Learn. EdSurge, May 2013.

Resnick, M., Martin, F., Berg, R., Borovoy, R., Colella, V., Kramer, K. et al. (1998). Digital manipulatives. Proceedings of the CHI '98 conference, Los Angeles, April 1998. https:/ / doi.org/10.1145/274644.274684

Simoncini, K., \& Lasen, M. (2018). Ideas about STEM among Australian Early Childhood professionals: How important is STEM in Early Childhood Education? International Journal of Early Childhood, 50(3), 353-369. https:/ / doi.org/10.1007/s13158-018-0229-5

Sternberg, R. J. (1996). Successful intelligence: How practical and creative intelligence determine success in life. New York, NY: Simon \& Schuster.

Sullivan, A., \& Bers, M.U. (2016). Robotics in the early childhood classroom: Learning outcomes from an 8-week robotics curriculum in pre-kindergarten through second grade. International Journal of Technology and Design Education, 26(3). https:/ / doi.org/10.1007/s10798-015-9304-5

Sullivan, F., \& Heffernan, J. (2016). Robotic Construction Kits as computational manipulatives for learning in the STEM disciplines, Journal of Research on Technology in Education, 48(2), 105-128, https:/ / doi.org/10.1080/15391523.2016.1146563

Thelen, E., \& Smith, L. (1994) A Dynamic Systems Approach to the Development of Cognition and Action, MIT Press.

Voogt, J., \& Roblin, N. J. (2012). A comparative analysis of international frameworks for 21st century competences: Implications for national curriculum policies, Journal of Curriculum Studies, 44(3), 299-321, https:/ / doi.org/10.1080/00220272.2012.668938

Vygotsky, L. S. (1978). Mind in society: The development of higher mental process. Cambridge, MA: Harvard University Press.

Weiskopf, D. A. (2010). Embodied cognition and linguistic comprehension. Studies in History and Philosophy of Science Part A, 41(3), 294-304. https:/ / doi.org/10.1016/j.shpsa.2010.07.005

\section{http://www.ejmste.com}

